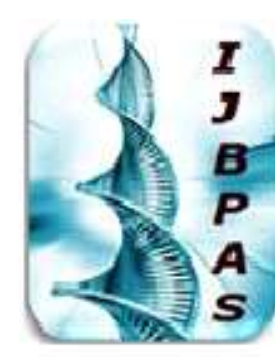

International Journal of Hiology, Pharmacy and Allied Seiences (IJBPAS) 'A Bridge Betuen Caboratory and Qnendo'

WWW.ijbpas.com

ASSESSMENT OF MATRIX METALLOPROTEINASE, REACTIVE OXYGEN SPECIES AND ANTIOXIDANT LEVELS IN COVID-19 INFECTION

\title{
SAEED $\mathrm{A}^{3}$, QAMAR $\mathbf{I}^{4}$, HAFEEZ $Z^{2}$, HAFEEZ MM ${ }^{1}$, ZAHID $^{1}$ AND MALIK $^{\mathbf{1}^{*}}$
}

1: Institute of Molecular Biology and Biotechnology (IMBB), The University of Lahore-Pakistan

2: University College of Medicine and Dentistry, The University of Lahore-Pakistan

3: Multan Medical and Dental College Multan-Pakistan

4: Rahber Medical and Dental College, Lahore-Pakistan

*Corresponding Author: Dr. Arif Malik (Ph.D): E Mail: arifuaf@yahoo.com; Cell: 0321-8448196;

Tel: +92 42-7515460-7, Fax: +92-42-7515519

Received $3^{\text {rd }}$ June 2020; Revised $8^{\text {th }}$ July 2020; Accepted $8^{\text {th }}$ Aug. 2020; Available online $1^{\text {st }}$ April 2021

https://doi.org/10.31032/IJBPAS/2021/10.4.5464

\begin{abstract}
OBJECTIVES: The COVID-19 pandemic, caused by novel SARS-CoV-2 virus, has taken millions of lives and still scientists are working day and night to sort out its sequence of pathological events in human body. This involved a super complicated chain of inflammatory and immune response events comprising epithelial cells and endothelium damage. The current study aims to assess the involvement of matrix metalloproteinase (MMPs) and reactive oxygen species (ROS) in the pathogenies of COVID-19 infection and their role as a prognostic mark. METHODOLOGY: The current cross sectional comparative study recruited total of one hundred participants that were further stratified into two groups. Group A consisted of fifty healthy individuals, whereas Group B enrolled fifty diagnosed cases of COVID-19 infection. Written consent was taken from the participants before including them in study. The levels of MMPs (3, 9, 12), ROS and antioxidants were measured by the ELISA kits in nominated laboratories of Hospitals under strict protocols set by the center of control (CDC). Statistical analysis was performed by using SPSS (V-21) and p-valve less than 0.05 considered significant. RESULTS: A significant rise in MMP-3, MMP-9 and MMP-12 levels were found in COVID-19 patients as compared to healthy controls. This was accompanied by elevated levels of oxidative stress marker Malondialdehyde (MDA) and reduced levels of anti-oxidants. CONCLUSION: The elevated levels of MMP-3, MMP-9, MMP-12, MDA and reduced
\end{abstract}


levels of anti-oxidants such as Glutathione (GSH), super oxide dismutase (SOD) and catalase (CAT) encourages scientists for more human targeted researches on the important role of MMPs in the development, progression, treatment and follow-up of COVID-19.

\section{Keywords: Anti-oxidants, COVID-19, Catalase, Glutathione, Matrix Metalloproteinase, Malondialdehyde, Super Oxide Dismutase}

\section{INTRODUCTION}

SARS-CoV-2 (severe acute respiratory syndrome coronavirus-2) was the reason behind the acute respiratory illness affected people in Wuhan city of china. COVID-19 was the name given to the disease resulted from this virus infection. COVID-19 gained global attention when it became pandemic due to its high contiguous potential among humans and the lake of targeted therapy [1]. COVID-19 varies from very mild disease with minimum or no symptoms to a very severe disease resulting in acute lung injury (ALI), acute respiratory distress syndrome (ARDS) and/or it may involve other organs. It caused death in about $2 \%$ of cases [2]. Reverse transcriptase polymerase chain reaction (RT-PCR) is standard test to establish a diagnosis of COVID-19 disease. A multistep and complicated extreme host immune and inflammatory response results in severe respiratory disease, this response named the cytokines storm. It comprises many pro-inflammatory chemokines and cytokines with leading role of interleukin-6 (IL-6) [3]. The immune response involves the
T-lymphocytes which produces CD4+ and CD8+ T-cells that produces targeted antibodies and destroys virus infected epithelium [4]. The process of inflammation includes extensive lung epithelial damage resulting in parenchymal injury caused by MMPs and cytokines. High levels of these MMPs and pro-inflammatory mediators will further activate macrophages and neutrophils to release free oxygen radicals and proteases that will further increase lung epithelial damage and increase vessels permeability leading to ALI. All these events will promote cytokines storm progression. IL-6 secreted by mast cell has regulatory effects on MMPs, and in turn both of them modulate ECM contraction and tissue fibrosis. Cytokines storm is the main factor behind the rapid progression of COVID-19 to severe state [5].

Protease enzymes such as Matrix Metalloproteinase (MMPs) that contains zinc have basic functions in various physiological and pathological processes including cell to cell signaling, cell growth and differentiation, tumors, new vessels growth, wound 
restoration, and ECM remodeling. MMPs has critical role in facilitating leukocytes invasion of lung parenchyma by breaking down the vessels basement membrane and ECM. Different cytokines especially IL-6 and many chemokines regulate MMPs activity and hence inflammatory process progression. MMPs will decide the survival time of inflammatory cells and have an important effect on each level of the inflammatory process [6]. Current researches on MMPs show involvement of MMP-3, MMP-9 and MMP-12 in the inflammatory response. Matrix Metalloproteinase-3 (MMP3, stromelysin-1), has a significant role in ECM degradation, regulation of cell signaling, regulation of immune and inflammatory reaction, cytokines and chemokines movements among cells. MMP3 has vital role in the host cell fusion process by SARS-CoV-2. MMP-3 was used in many diseases such as rheumatoid arthritis and cancers to follow the disease progression status. Its role in lung epithelial and endothelial injury and healing process is prominent and demonstrated by many studies. MMP-3 is released from endothelium, fibroblast and macrophages in response to cytokines and inflammatory cells [7]. The host reaction to SARS-CoV-2 includes immune cells and protease activity that is regulated by MMPs activity. Hoffmann and his colleagues shown MMP-3 positive association between SARS-CoV-2 patients and those patients with COVID-19 negative tests, a feature that can be used to establish diagnosis of COVID-19 and follow its progression Matrix Metalloproteinase 12 (MMP-12, interstitial lysine), is involved in elastin regulation, ECM regulation, activation of chemokines and cytokines and also it regulates proteases; hence promoting pulmonary inflammatory process and epithelial damage [8] MMP-12 has vital role in regulation of inflammation and its resolution. MMP-12 is secreted chiefly by macrophages, osteoclasts and chondrocytes. Zhou et al has shown increase MMP-12 levels in the CNS during coronavirus induced encephalitis which involve blood brain barrier degradation and increased immune cells recruitments to the inflammatory areas of the brain [9]. Many nonspecific inhibitors of MMPs and the agents that can inhibit the ongoing cascade of inflammatory process have been studied and found to have role in limiting the lung injury. Among those aprotnin, tetracyclines and doxycycline are commonly used in clinical practice, and minocycline, glucosamine and marimastat are still in clinical trial studies [10]. Keeping in mind the role of MMPs in 
pathophysiology of inflammation and the resulted consequences; further studies in humans are required to fully understand the role of MMPs inhibitors and their possible role in the prognosis of complex COVID-19 disease particularly the ALI/ARDS.

Oxidative stress plays an important role in regulation of cell repair and controlling the immune response which together contributes to the progression of lung pathology either by adding in the oxidants levels or by decreasing the antoxidant levels [11]. This leads us to the conclusion that in COVID-19 patients, the role of oxidative stress is prominent and it may increase the severity of illness especially in the presence of other chronic diseases. The increasing levels of free radical and lipid peroxides will result in elevated levels of Malondialdehyde (MDA) causing more cell damage. Anti-oxidant Glutathione (GSH) is vital for marinating the epithelial cell integrity thus having an important protective anti-oxidant role; this will be supported by the role of super oxide dismutase (SOD) and catalase (CAT) in preventing cellular injury [12]. SARS-CoV-2 like other viruses uses oxidative stress pathways to ease their entry and survival inside the cell. Thus success or failure to the inflammatory and immune response to the virus is highly influenced by the balance between the oxidant and the antioxidant levels, components of oxidative stress. The current study was designed to assess the variation of MMPs, MDA and anti-oxidative stress markers in COVID-19 patients having moderate level of severity.

\section{METHODOLOGY}

The current cross sectional comparative study included admitted cases of confirmed COVID-19 infection that were fall in the moderate level of severity. This study was conducted in three months from March, 2020 to June, 2020 after the approval of Institutional Review Board (IRB), Institute of Molecular Biology and Biotechnology (IMBB) The University of Lahore. Total of one hundred participants were analyzed and further divided in two equal groups Control group had age and sex matched healthy individual as compare to the COVID-19 infected group labelled as subjects. Participants having any other inflammatory disease like chronic joints, renal, skin or hematological diseases were excluded from the study. Samples were taken at the time of admission to determine the levels of Matrix Metalloproteinase (MMP-3 MMP-9 and MMP-12) in each sample to compare them with that of control patients. Also the levels of oxidative stress markers such as Malondialdehyde (MDA) and the other anti- 
oxidative markers were estimated in COVID19 infected patients. All of the reagents and chemicals were of analytical grade obtained from the Sigma/Invitrogen Chemical Co. (St. Louis, Mo, USA). The levels of MMP-3, MMP-9 and MMP-12 were determined by commercially available humane ELISA kit method (by Muglumi).

The data was analyzed by using SPSS (Version 21). Continuous Variables was described in terms of mean \pm standard deviation (SD) like age, MMP-3, 9, 12, MDA, GSH, SOD and CAT. Paired t-test was used for comparison between the groups. chi-square test was applied where comparison of categorical variables is needed. the level of $\mathrm{p}<0.05$ was considered statistically significant.

\section{RESULTS}

The findings of the study showed increased levels of matrix metalloproteases in the COVID-19 positive patients when compared with the healthy controls that signifies the increased extracellular matrix
(ECM) degradation. Participants were divided into three age groups. Male to female ratio was 56:44 (Table 1).

Levels of MMP 3, 9 and 12 were significantly higher in patients $(2.12 \pm 0.11$ $\mathrm{ng} / \mathrm{ml}, 141.41 \pm 7.43 \mathrm{ng} / \mathrm{ml}, 5.55 \pm 0.59 \mathrm{ng} / \mathrm{ml}$, $p$-value $=0.021, \quad 0.013$ and 0.016$)$ as compared to controls $(0.296 \pm 0.08 \mathrm{ng} / \mathrm{ml}$, $28.34 \pm 5.32 \mathrm{ng} / \mathrm{ml}$ and $0.433 \pm 0.03 \mathrm{ng} / \mathrm{ml}$ ) respectively. Levels of oxidative stress markers were also significantly differed in both groups.

Levels of Malondialdehyde (MDA) were significantly higher in COVID-19 patients $(6.40 \pm 0.89 \quad \mathrm{nmol} / \mathrm{ml})$ when compared with controls $(1.40 \pm 0.349)$. While levels of all anti-oxidative markers remained significantly lower $(0.33 \pm 0.02 \mathrm{IU} / \mathrm{ml}$, $3.87 \pm 1.87 \mu \mathrm{mol} / \mathrm{ml}$ and $3.11 \pm 0.6 \mu \mathrm{mol} / \mathrm{ml} ; p$ value $0.038,0.005$, and 0.023 respectively) in the COVID-19 patients highlighting imbalance in between the oxidative and antioxidative status in the patients with positive coronavirus (Table 2).

Table 1: Age and Gender Distribution among Groups

\begin{tabular}{|c|c|c|c|c|}
\hline Individual factors & Category & \multicolumn{3}{|c|}{ Frequency (\%) } \\
\hline \multirow[b]{2}{*}{ Disease Status } & & $\begin{array}{c}{ }^{1} \text { Controls } \\
n=50\end{array}$ & $\begin{array}{c}{ }^{2} \text { subjects } \\
n=50\end{array}$ & $\begin{array}{c}\text { Total } \\
N=100\end{array}$ \\
\hline & Healthy & $50(100 \%)$ & O (0\%) & $50(50 \%)$ \\
\hline \multirow{3}{*}{ *Age } & COVID-19 Positive & $0(0 \%)$ & $50(100 \%)$ & $50(50 \%)$ \\
\hline & $30-40$ years & $14(28 \%)$ & $15(30 \%)$ & $29(29 \%)$ \\
\hline & $41-50$ years & $14(28 \%)$ & $13(26 \%)$ & $27(27 \%)$ \\
\hline \multirow{3}{*}{ Gender } & 51-60 Years & $22(44 \%)$ & $22(44 \%)$ & $44(44 \%)$ \\
\hline & Male & $28(56 \%)$ & $28(56 \%)$ & $56(56 \%)$ \\
\hline & Female & $22(44 \%)$ & $22(44 \%)$ & $44(44 \%)$ \\
\hline
\end{tabular}

*Age is stratified into three groups; 1. Healthy population; 2. PCR positive cases of COVID-19 


\begin{tabular}{|c|c|c|c|c|}
\hline \multicolumn{5}{|c|}{ Table 2: Comparison of Variables Between Both Groups } \\
\hline \multicolumn{2}{|c|}{ Variables } & \multicolumn{2}{|c|}{ Mean \pm S.D } & \multirow{2}{*}{ *P-Value } \\
\hline Category & Markers & Controls $(n=100)$ & Patient $(n=100)$ & \\
\hline Oxidative stress & MDA nmol/ml & $1.40 \pm 0.349$ & $6.40 \pm 0.89$ & 0.003 \\
\hline \multirow[t]{3}{*}{ Anti-oxidants } & SOD IU/ml & $\mathbf{1 . 1 7} \pm \mathbf{0 . 1 3}$ & $0.33 \pm 0.02$ & 0.038 \\
\hline & GSH $\mu \mathrm{mol} / \mathrm{ml}$ & $10.72 \pm 2.65$ & $3.87 \pm 1.87$ & 0.005 \\
\hline & $\mathrm{CAT} \mu \mathrm{mol} / \mathrm{ml}$ & $5.65 \pm 1.06$ & $3.11 \pm 0.6$ & 0.023 \\
\hline \multirow[t]{3}{*}{ Metalloproteinase } & MMP-3 ng/ml & $0.296 \pm 0.08$ & $2.12 \pm 0.11$ & 0.021 \\
\hline & MMP-9 ng/ml & $28.34 \pm 5.32$ & $141.41 \pm 7.43$ & 0.013 \\
\hline & MMP-12 ng/ml & $0.433 \pm 0.03$ & $5.55 \pm 0.59$ & 0.016 \\
\hline \multicolumn{5}{|c|}{${ }^{*}$ Independent $t$-test was used to assess the significance of variance } \\
\hline
\end{tabular}

\section{DISCUSSION}

To find a targeted therapeutic agent that can break the process of intense inflammatory and immune reaction in COVID-19 patient there was multiple studies ongoing to point out the proinflammatory mediator (more attention is paid to MMPs) and its serum levels that can have effect on pathophysiology of COVID-19 [13]. Yuki and his colleagues mentioned that cytokines released from virus infected pulmonary epithelium (such as SARS-CoV-2 virus) has chemoattractant properties for different leukocytes including neutrophils [14]. In COVID-19 this massive reaction of inflammatory and immune cells will add on to the development of cytokines storm and leads to the pathological finding of epithelial and endothelial injury and the subsequent tissue remodeling events.

Shi and his colleagues described the increased in MMP-3, IL-1 $\beta$ and IL-6 levels in patients with COVID-19 disease [15]. Nissinen and his colleagues had shown that
MMP-3 deficient mice are safe from the immune and inflammatory stimulation to some extent [16]. This emphasized the regulatory function of MMP-3 in lung tissue damage and restoration. Warner and his colleagues described the regulatory effects of MMP-3 on chemokines and cytokines in ALI and ARDS in COVID-19. Shi et al in their study compared MMP-3 levels in SARSCoV-2 infected patients with those who are SARS-CoV-2 negative and came out with the finding that MMP-3 is useful marker for the monitoring of COVID-19 disease state from diagnosis through progression and ending with follow-up. MMPs and other protease enzymes along with other pro-inflammatory mediators of cytokines storm will predict the progression to severe disease in COVID-19 [17]. McCawley and his colleagues also highlighted the effects of the high levels of MMPs in COVID-19 patients and its relation to the inflammatory process ongoing in their lungs and the prominent regulatory role of MMP-3 during this response [18]. The 
findings of study done by Shi et al, described the role of MMP-3 in fusion of coronavirus to the host cell, thus supporting the important function of MMP-3 in host cell fusion in SARS-CoV-2 infection. Epithelial damage by the effects of immune and inflammatory cells mediated by MMPs and other proinflammatory mediators of cytokines storm will lead to the development of ALI and ARDS in COID-19 patients [15].

Researches demonstrated increased MMPs expression in murine mice coronavirus induced CNS encephalitis models. These MMPs were having noticeable ECM remodeling function. Also the critical role of MMPs in facilitating virus invasion into the CNS, involvement in blood brain barrier destruction, neutrophils and cytokines trafficking and regulation during CNS coronavirus infection [19]. The relation between MMPs mediated cell injury and SARS-CoV-2 infection was supported by the finding of rapid increased in Kawasaki disease cases in Italy during the COVID-19 pandemic [20]. The earlier information about the vital role of the MMPs and cytokines storm (such as IL-6) in regulation of inflammatory reaction chain was reinforced and supported by Karakurt and his colleagues comparison study where a SARS-CoV-2 infected lung epithelium was compared with mock-infected model cell [21]. Solun et al explained the critical role of MMPs in epithelial injury and restoration during the course of COVID-19 disease, and urged for the need of more human clinical studies on the possibilities of using some non-specific MMPs inhibitors for treatment of ALI and ARDS in SARS-CoV-2 infected patients [2235]. The finding of high cytokines and cytokines storm in COVID-19 patients pointed to crucial role of MMPs and proinflammatory mediators in the disease process of COVID-19. The virulence level of SARS-CoV-2 was linked to high levels of MMPs (chiefly MMP-3 and -9) associated with high chemokines regulation [12]. New researches are vital to completely identify the role of MMPs in the pathophysiology of COVID-19 induced ALI/ARDS. These data are essential to define what type of metalloproteinase might be regulated, at which level of the infection, and what MMPs level might be ideal for the restoration of the affected tissues.

\section{CONCLUSION}

The study showed a positive relation between MMP-3, 9 and -12 levels in COVID-19 positive infection patients and the controls. The finding of elevated serum levels of MMPs along with the supporting data from previous studies may have a vital 
role in discovering more targeted therapeutic modalities that can be beneficial in COVID19 avoidance, treatment and/or preventing progression to more severe disease state. Together with our results including the imbalanced oxidative stress markers levels and the high levels of the immune and inflammatory mediator points towards the active inflammatory state of COVID-19 which may progress to cytokines storm. Therefore, more advance and more targeted human clinical studies with more focus on MMPs role is indicated for understanding of COVID-19 pathophysiology and it is believed it will have a great contribution in the management of COVID-19.

\section{ACKNOWLEDGEMENTS}

Authors are highly thankful and pay their gratitude to Mr. Awais Raoof, Chairman BOG, The University of Lahore for supporting and providing financial assistance for the current project.

\section{CONFLICT OF INTEREST}

Authors declare no conflict of interests.

\section{REFERENCES}

[1] Korber, B., Fischer, W. M., Gnanakaran, S., Yoon, H., Theiler, J., Abfalterer, W., \& Hastie, K. M. (2020). Tracking changes in SARS-CoV-2 Spike: evidence that D614G increases infectivity of the COVID-19 virus. Cell, 182(4), 812-827.

[2] Vannabouathong, C., Devji, T., Ekhtiari, S., Chang, Y., Phillips, S. A., Zhu, M., \& Bhandari, M. (2020). Novel coronavirus COVID-19: current evidence and evolving strategies. The Journal of bone and joint surgery. American volume, 102(9), 734.

[3] Mehta, P., McAuley, D. F., Brown, M., Sanchez, E., Tattersall, R. S., Manson, J. J., \& HLH Across Speciality Collaboration. (2020). COVID-19: consider cytokine storm syndromes and immunosuppression. Lancet (London, England), 395(10229), 1033.

[4] Manna, S., Baindara, P., \& Mandal, S. M. (2020). Molecular pathogenesis of secondary bacterial infection associated to viral infections including SARSCoV-2. Journal of Infection and Public Health.

[5] George, P. M., Wells, A. U., \& Jenkins, R. G. (2020). Pulmonary fibrosis and COVID-19: the potential role for antifibrotic therapy. The Lancet Respiratory Medicine.

[6] Ulrich, H., \& Pillat, M. M. (2020). CD147 as a target for COVID-19 treatment: suggested effects of azithromycin and stem cell 
engagement. Stem Cell Reviews and Reports, 1-7.

[7] Kuźnik-Trocha, K., Winsz-Szczotka, K., Komosińska-Vassev, K., JuraPółtorak, A., Kotulska-Kucharz, A., Kucharz, E. J., ... \& Olczyk, K. (2020). Plasma Glycosaminoglycan Profiles in Systemic Sclerosis: Associations with MMP-3, MMP-10, TIMP-1, TIMP-2, and TGF-Beta. BioMed Research International, 2020.

[8] Zhou, F., Yu, T., Du, R., Fan, G., Liu, Y., Liu, Z., ... \& Guan, L. (2020). Clinical course and risk factors for mortality of adult inpatients with COVID-19 in Wuhan, China: a retrospective cohort study. The lancet.

[9] Shi, S., Su, M., Shen, G., Hu, Y., Yi, F., Zeng, Z., ... \& Xie, X. (2020). Matrix metalloproteinase 3 as a valuable marker for patients with COVID-19. Journal of medical virology.

[10] Ali, J., Ali, Q., Hafeez, M. M., \& Malik, A. (2020). Clinical features, diagnosis and treatment of COVID19. Biol Clin Sci Res J, 2020, e032.

[11] Yan, Z., \& Spaulding, H. R. (2020). Extracellular superoxide dismutase, a molecular transducer of health benefits of exercise. Redox biology, 101508.
[12] Zhou, Y., Tan, F., Li, C., Li, W., Liao, W., Li, Q., ... \& Zhao, X. (2019). White peony (fermented Camellia sinensis) polyphenols help prevent alcoholic liver injury via antioxidation. Antioxidants, 8(11), 524.

[13] Alexander, S. P. H., Armstrong, J., Davenport, A. P., Davies, J., Faccenda, E., Harding, S. D., \& Spedding, M. J. (2020). A rational roadmap for SARS-CoV-2/COVID-19

pharmacotherapeutic research and development. IUPHAR review "XXX". British Journal of Pharmacology.

[14] Yuki, K., Fujiogi, M., \& Koutsogiannaki, S. (2020). COVID-19 pathophysiology: A review. Clinical immunology, 108427.

[15] Shi, S., Su, M., Shen, G., Hu, Y., Yi, F., Zeng, Z., \& Xie, X. (2020). Matrix metalloproteinase 3 as a valuable marker for patients with COVID-19. Journal of medical virology.

[16] Nissinen, L., \& Kähäri, V. M. (2014). Matrix metalloproteinases in inflammation. Biochimica et Biophysica Acta (BBA)-General Subjects, 1840(8), 2571-2580. 
[17] Kanbarkar, N., \& Mishra, S. (2020). Matrix metalloproteinase inhibitors identified from Camellia sinensis for COVID-19 prophylaxis: an in silico approach. Advances in Traditional Medicine, 1-16.

[18] McCawley, L. J., \& Matrisian, L. M. (2001). Matrix metalloproteinases: they're not just for matrix anymore!. Current opinion in cell biology, 13(5), 534-540.

[19] Rempe, R. G., Hartz, A. M., \& Bauer, B. (2016). Matrix metalloproteinases in the brain and blood-brain barrier: versatile breakers and makers. Journal of Cerebral Blood Flow \& Metabolism, 36(9), 1481-1507.

[20] Verdoni, L., Mazza, A., Gervasoni, A., Martelli, L., Ruggeri, M., Ciuffreda, M., \& D'Antiga, L. (2020). An outbreak of severe Kawasaki-like disease at the Italian epicentre of the SARS-CoV-2 epidemic: an observational cohort study. The Lancet.

[21] Karakurt, H. U., \& Pınar, P. İ. R. (2020). Integration of transcriptomic profile of SARS-CoV-2 infected normal human bronchial epi-thelial cells with metabolic and protein-protein interaction networks. Turkish Journal of Biology, 44(3), 168.
[22] Solun, B., \& Shoenfeld, Y. (2020). Inhibition of metalloproteinases in therapy for severe lung injury due to COVID-19. Medicine in Drug Discovery, 100052.

[23] Hafeez M, Yasin T, Safdar U, Waquar S, Rana M, Malik A. An evidence based assessment of most common risk factors of myocardial infraction: analysis from a local population. Biol Clin Sci Res J 2020(1):e044.

[24] Khalil R, Ali Q, Hafeez M, Malik A. Phenolic acid profiling by rp-hplc: evaluation of antibacterial and anticancer activities of Conocarpus erectus plant extracts. Biol Clin Sci Res J 2020(1):e010.

[25] Hameed B, Ali Q, Hafeez MM, Malik A. Antibacterial and antifungal activity of fruit, seed and root extracts of Citrullus colocynthis plant. Biol Clin Sci Res J. 2020;33.

[26] Ali J, Ali Q, Hafeez MM, Malik A. Clinical features, diagnosis and treatment of COVID-19. Biol Clin Sci Res J. 2020;2020:e032.

[27] Siddique A, Fateh A, Idrees N, Hafeez MM, Ali Q, Malik A. The epidemics of COVID-19. Biol Clin Sci Res J. 2020:e030. 
[28] Rashid M, Kari M, Rashid R, Rana M, Amjad A, Hafeez M. Uterine artery doppler indices as predictive measures for the pre-eclampsia and intrauterine growth restriction. Biol Clin Sci Res J; 2020(1):e023.

[29] Omer M, Malik S, Anjum M, Riaz A, Ali R. Diagnostic accuracy of ultrasound in detecting meniscal tears taking magnetic resonance imaging as gold standard. Biol Clin Sci Res J 2020(1):e040.

[30] Ali Q, Khalil R, Nadeem M, Hafeez, MM, Malik, A. Antibacterial, antioxidant activities and association among plant growth related traits of Lepidium draba. Biol Clin Sci Res J. 2020:011.

[31] Khalid A, Anjum M, Daraaz U, Hussain K, Omer M. Predictive accuracy of cervical length in mid trimester on transabdominal ultrasound for cesarean section. Biol Clin Sci Res J 2020(1): 0 043.

[32] Chudhary H, Amin A, Malik M, Hafeez M, Rana M, Malik A. Risk assessment of non-conventional contributory factors in onset of diabetes mellitus type II. Biol Clin Sci Res J 2020(1):e036.
[33] Ali S, Gillani S, Afzal M, Parveen K. Assessment of nurses management skills for critically ill patients. Biol Clin Sci Res J 2020(1):e013.

[34] Tabassum S, Bibi T, Tariq F, Tariq S, Raza S, Hafeez M, Rana M. Unusual leukemoid reaction in a covid-19 patient: a case report. Biol Clin Sci Res J 2020(1):e034.

[35] Mady A, Ramdan O, Al Yousef R, Ishag A, Bakirova G, Kuhail A, Shahzad S, El-Etreby W, Mumtaz S, Almozainy S, Palacio K, Aldamahshi D, Alcazar A, Alodat M, Abdelrahman B, Harthy A. COVID 19 critical care training surge experience for physicians in riyadh health cluster one, Saudi Arabia. Biol Clin Sci Res J 2020(1):e041. 